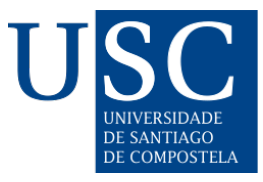

\title{
Urbanismo sostenible. El camino de las ciudades en la Agenda 2030
}

Sustainable urbanism. The path of cities in the 2030 Agenda

Manuel García Docampo

Universidade da Coruña, España

docampo@udc.es

\section{Resumen}

El presente ensayo realiza un repaso analítico por la evolución de las ciudades, desde la era preindustrial hasta la postindustrial, deteniéndose en sus problemáticas y las formas de producción del espacio. Asimismo, se efectúa un estudio de las diferentes corrientes de pensamiento del urbanismo, escrutando sus postulados y proposiciones. Desde el materialismo al postmaterialismo. Del Posturbanism al New Urbanism. La ciudad, como escenario de conflictos, está en el centro de todo debate sobre la sostenibilidad y el respeto al medio ambiente. En los últimos años se ha abierto paso un urbanismo sostenible que pone el foco de atención en la necesidad de referirse a la mejora de toda la especie humana, de ésta y próximas generaciones y de hacerlo en armonía con el bienestar del resto de las especies que habitan el planeta. La Agenda 2030 es el marco perfecto para el desarrollo de este nuevo paradigma urbanístico.

Palabras clave: Ciudad; urbanismo; sociología urbana; sostenibilidad; urbanismo sostenible.

\begin{abstract}
This essay makes an analytical review of the evolution of cities, from the pre-industrial to the postindustrial era, focusing on their problems and the forms of production of space. Likewise, a study is made of the different currents of thought in urbanism, scrutinizing their postulates and propositions. From materialism to post-materialism. From Posturbanism to New Urbanism. The city, as the scene of conflicts, is at the center of any debate on sustainability and respect for the environment. In recent years, sustainable urbanism that focuses on the need to refer to the betterment of the entire human species, of this and future generations, and to do so in harmony with the well-being of the rest of the species that inhabit the planet, has been gaining ground. The 2030 Agenda is the perfect framework for the development of this new urban planning paradigm.
\end{abstract}

Keywords: City; urban planning; urban sociology; sustainability; sustainable urbanism.

\section{Sumario}
1. Introducción
2. La ciudad como producto
3. La ciudad como escenario

Copyright $\odot$ Universidade de Santiago de Compostela. This is an open access article distributed under the terms of the Creative Commons Attribution-NonComercial-NoDerivatives 4.0 International (CC BY-NC-ND 4.0) License. 

4. La ciudad deficiente
5. La ciudad planificada
6. La ciudad sostenible
7. La ciudad agendada
8. Conclusiones

\section{Contents}
1. Introduction
2. The city as a product
3. The city as a stage
4. The poor city
5. The planned city
6. The sustainable city
7. The scheduled city
8. Conclusions

\section{INTRODUCCIÓN}

En el año 2015 se firma un acuerdo internacional, conocido como Agenda 2030, con el objetivo de lograr un planeta más sostenible. En el mismo, las ciudades aparecen con un especial protagonismo. El objetivo no 11 (de los 17 que consta el acuerdo) pretende que toda la población urbana tenga acceso a la vivienda, al transporte y a los espacios verdes, con diseños inclusivos y reduzca desastres naturales, en el contexto de un urbanismo participado, con un patrimonio protegido y un cuidado medioambiente (ONU, 2015).

¿Se trata de otra declaración de intenciones para que los dirigentes aparezcan juntos en una foto? ¿Son esas las metas pertinentes y/o es éste el momento? Vamos a tratar de responder a estas y otras cuestiones repasando algunos aspectos centrales de la sociología urbana. Revisaremos, para ello, tanto la situación de las ciudades como la del planeamiento urbanístico que trata de dar solución a las deficiencias detectadas.

Hablar de ciudad, en singular, resulta un eufemismo poco eficiente. En cada una, habitan muchas otras: la ciudad como producto, es también la que es escenario de los conflictos; la de las deficiencias, es también la planificada; la que está tan necesitada de un rumbo sostenible es la que figura en las agendas de las altas esferas de la política. Ese va a ser el guion de reflexión y, aunque no nos detengamos excesivamente en las interpretaciones históricas, sí marcaremos las tendencias existentes, de tal manera que permitan una prognosis de futuro, tanto de la sociedad, como de la ciudad y de su planeamiento

La ciudad tiene una fuerte tendencia entrópica al caos. La lógica de mercado del suelo colisiona frecuentemente con el interés colectivo. Los actores que intervienen en la producción del suelo (Figura 1) defienden sus intereses en una latente y permanente tensión. El planeamiento urbanístico surge vocacionalmente para frenar esas inercias manteniendo así un intenso pulso con éstas. Planeamiento y realidad urbana son, por tanto, dos realidades dialécticamente relacionadas que requieren ser entendidas en ese marco conjunto. Para realizar el diagnóstico precisamos dar cuenta de la situación de ambos elementos en el momento actual y de cuál es su previsión de futuro. Eso requiere a su vez, entender la función social de las ciudades y sus lógicas de conflicto. 
Figura 1. Agentes intervinientes en la producción del espacio

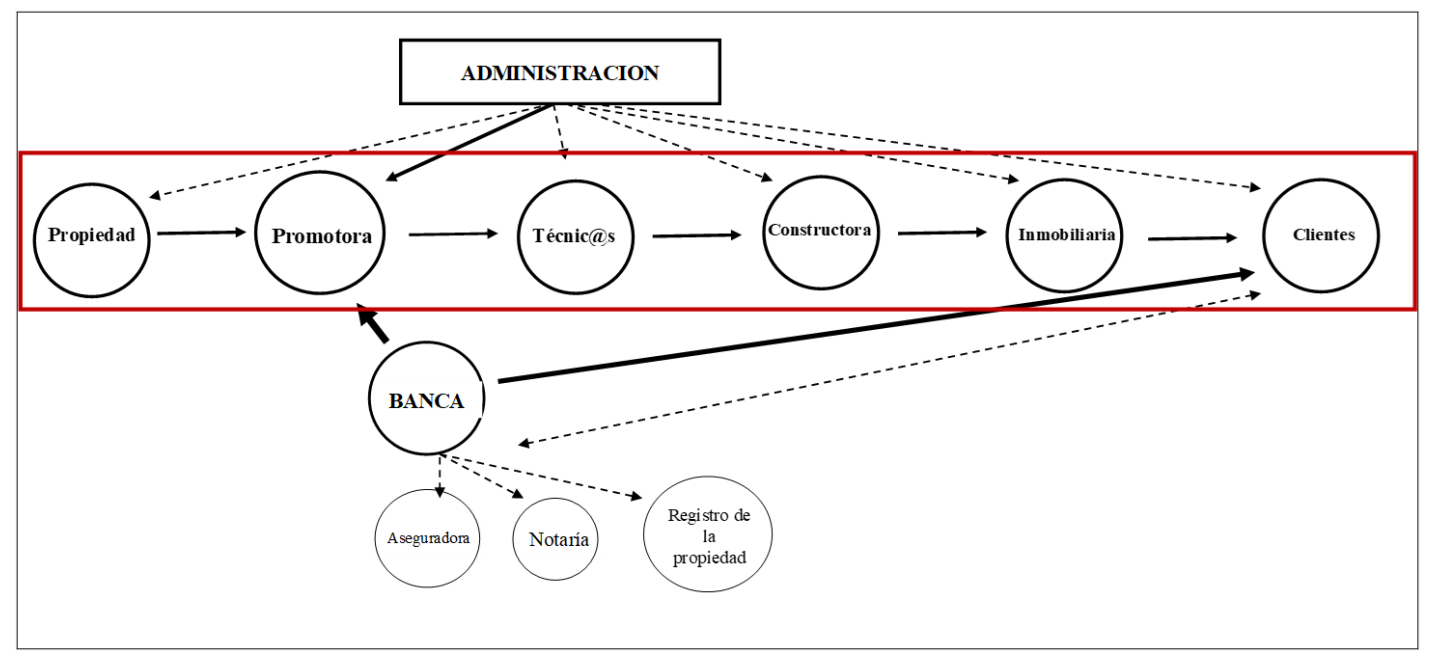

Fuente: Elaboración propia

\section{LA CIUDAD COMO PRODUCTO}

No es posible entender las ciudades, su evolución y necesidades, descontextualizadas de la comprensión general de la sociedad en la que se insertan porque no solo son un producto social sino uno de los constructos más elaborados y exquisitos que haya generado nunca. En ellas trabaja, se divierte o descansa una creciente proporción de población del planeta. Ese hábitat es un auténtico ecosistema de cemento en el que se desarrolla la acción humana; es heterogéneo y se mantiene en permanente proceso de transformación y readaptación y, lo que es especialmente relevante, es resultado de la sociedad que lo crea, pero, a su vez, constriñe su conducta, como la dual estructura que en realidad es (Giddens, 2006).

No hay manera de concebir la urbe romana, la medieval, la ilustrada o la contemporánea, si no es dando cuenta de las características de sus sociedades y de las transformaciones que supusieron respecto a sus predecesoras. En su interior, las estructuras de poder (y propiedad) gestionan las actividades de sus residentes y visitantes. Prohíben, activan, invisibilizan, legalizan, fiscalizan, promueven, derriban, ... El poder actúa siempre, sea o no legítimo. Los ciudadanos desempeñan sus roles, incluso poniendo y cambiando las estructuras de poder. Entretanto, viven, trabajan, se divierten, descansan, etc. Poder y ciudadanos ejercen un entramado complejo de tensiones que confluyen en intereses diversos produciendo y gestionando el espacio urbano. La ciudad, tal como sugería el conocido diagrama de Krier (1992, p. 27), es la suma de todo ello, público y privado, conjugado en un mismo tejido.

La lógica de que la ciudad es un producto social implica que, si la sociedad cambia, la ciudad lo hará también. Los cambios inherentes a cada sociedad son denominados en sociología como Cambios Sociales. Éstos, a diferencia de otros acontecimientos cotidianos son, por definición, cambios estructurales que suelen afectar, en general, aunque con diferentes cronologías, a todas las sociedades.

La estructura de la ciudad que impresiona por su complejidad, tiene por base a la naturaleza humana, de la cual es expresión. Sin embargo, esta estructura ya formada actúa a su vez sobre sus habitantes, ubicados frente a una realidad exterior con la cual tiene que contar. (Chueca Goitia, 1968, p. 32) 
La ciudad recoge y se reproduce a partir de esas transformaciones. Intentar explicarlas ha sido una tarea recurrente de la Sociología ${ }^{1}$. Una de las propuestas más básicas y asumidas es la de Daniel Bell (1973). En su obra El advenimiento de la Sociedad Postindustral expone los tres estadios por los que van pasando todas sociedaddes: agrario, industrial y postindustrial. Las dos primeras no precisan mucha explicación, la tercera, la postindustrial, era una propuesta innovadora en aquel momento (los setenta del siglo XX). Según él, ya se percibían en la mayor parte de los países de la OCDE una serie de características diferentes a la de períodos anteriores. Entre ellos, los más relevantes eran que se trata de una economía focalizada en conocimientos teóricos y tecnológicos.

Figura 2. Características de las sociedades según D. Bell

\begin{tabular}{|c|c|c|c|}
\hline $\begin{array}{l}\text { Sociedad } \\
\text { Tema }\end{array}$ & Preindustrial & Industrial & Postindustrial \\
\hline Base económica & Agraria & Industrial & Servicios \\
\hline Clases & Estamentos & $\begin{array}{l}\text { Burguesía y Proletariado en } \\
\text { conflicto }\end{array}$ & $\begin{array}{l}\text { Clases profesionales e } \\
\text { técnicas }\end{array}$ \\
\hline Principio axial & Orden & Desarrollo económico. & Conocimiento teórico \\
\hline $\begin{array}{l}\text { Orientación } \\
\text { futura }\end{array}$ & $\begin{array}{l}\text { Satisfacción } \\
\text { necesidades }\end{array}$ & Incrementar producción & Incrementar tecnología \\
\hline $\begin{array}{l}\text { Tomas de } \\
\text { decisión }\end{array}$ & Absolutismo & Democracia liberal & $\begin{array}{ll}\text { Nueva } & \text { tecnología } \\
\text { intelectual } & \end{array}$ \\
\hline
\end{tabular}

Fuente: Elaboración propia, basada en Bell (1973)

Hasta la revolución industrial, los seres humanos habitaban, además de en espacios rurales, en ciudades que no suponían una ruptura medioambiental, sino un ecosistema particular que enriquecía el entorno. En las ciudades medievales, por ejemplo, aunque físicamente bien separadas, por sus murallas, del entorno rural circundante, vivían múltiples especies de animales domésticos (y salvajes) $^{2}$.

La ciudad preindustrial se caracteriza por su crecimiento moderado, con tasas similares a la de los espacios rurales circundantes. Rodeada de murallas, las reformas interiores puntuales aliviaban sólo parcialmente el problema sanitario interior. El crecimiento demográfico de las ciudades medievales se mantuvo hasta bien entrada la era industrial moderna. Predominaron los saldos moderadamente positivos, interrumpidos por frecuentes crisis de mortalidad catastrófica.

La ciudad creció inusitadamente a partir de la aparición de las fábricas ${ }^{3}$. En un primer momento, la industria fabril era muy intensiva en mano de obra ${ }^{4}$. Las fábricas comenzaron a tener protagonismo espacial. A su alrededor, las residencia de las trabajadoras y trabajadores, generando barriadas urbanas cada vez más extensas. A su vez, crecieron las infraestructuras viarias que permitían traer y llevar mercancías, además de personas. Desde el siglo XIX, muchas ciudades europeas literalmente dispararon sus ratios de crecimiento. Londres tenía a principios del XIX un millón de habitantes. Doscientos años después se acerca a los 8 millones. Madrid, de 300 mil a casi 4 millones. Otras ciudades, como Nueva York pasan de 3 a 17 millones. En el caso de Galicia, Vigo ostenta el récord de crecimiento en el siglo XX, entre todas las ciudades europeas, pasando de poco más de 20.000 habitantes a unos 300.000 a finales de ese siglo.

Para humanizar y mejorar la calidad de vida, el urbanismo incorporó parques, equipamientos públicos, viarios de calidad y mejores estándares constructivos. Un "verde", en el mejor de los 
casos, pensado para el disfrute humano. Fundamentalmente, la ciudad se diseñaba pensando en la movilidad, con viarios que ocupan una buena parte de su superficie. El parque o jardín aparece como una isla rodeada de vías, cemento, espacios inertes. Aunque muchas de esas zonas verdes tienen una enorme riqueza en flora y fauna. Pero son solo eso: islas.

Figura 3. Evolución de la población urbana en el mundo

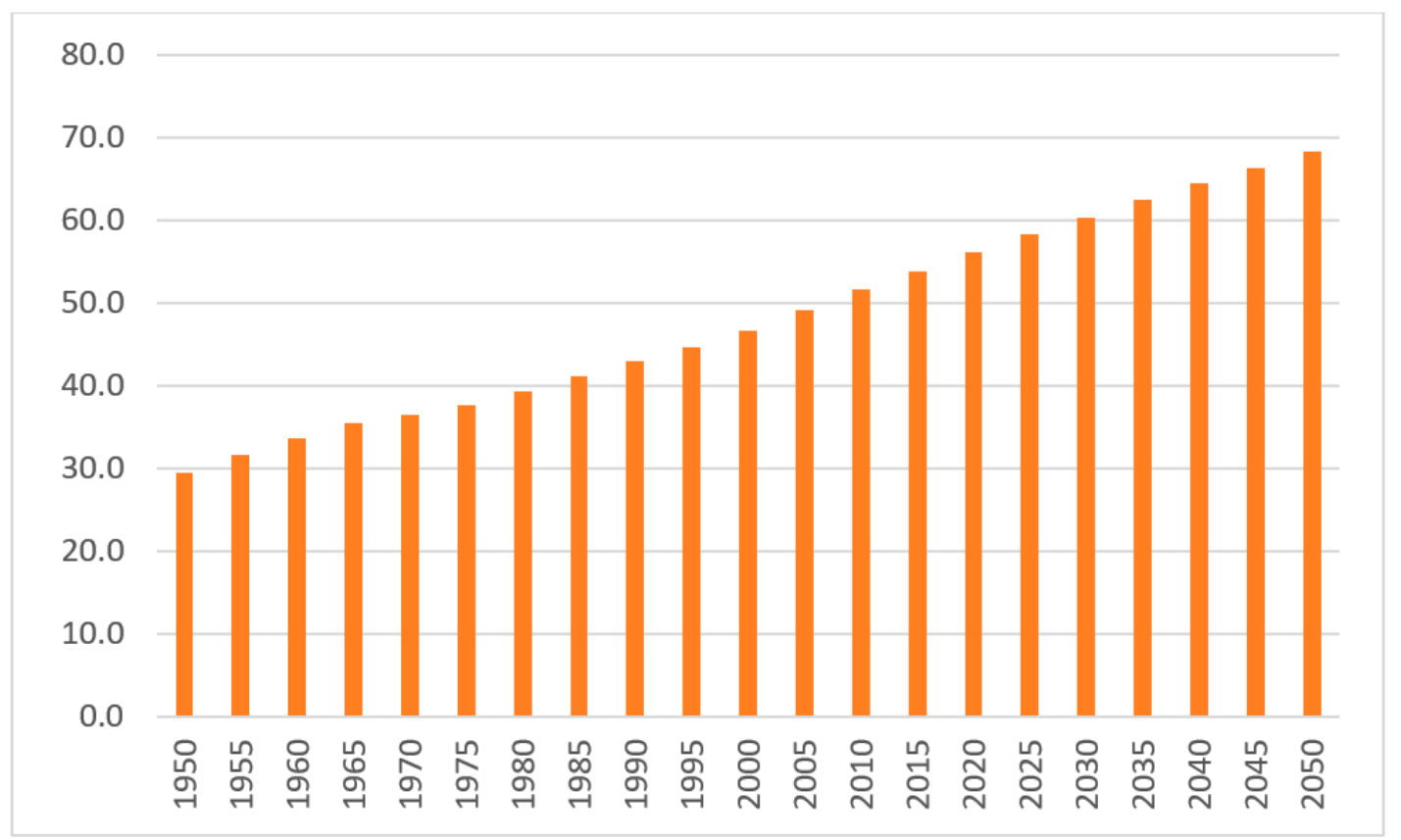

Fuente: Elaboración a partir de datos del Wordl Urbanization Prospect (UU.NN., 2018)

Pero la evolución social ha dejado también atrás la hegemonía industrial. Aparece así, una nueva ciudad postindustrial, que ha sustituido las chimeneas de las fábricas, por oficinas, centros comerciales y de ocio, en sus polígonos industriales. Esa ciudad demanda incorporar la sostenibilidad medioambiental como objetivo fundamental. Está regida por un nuevo paradigma urbanístico en la que lo verde no es un reducto, sino el todo. La ciudad no se entiende como una ruptura en el territorio, sino como un continuum del mismo. Además, se suburbaniza: aparecen polígonos residenciales dormitorio, amplias periferias que desconcentraron parte de la población urbana y la integra en antiguos espacios rurales, generando intersecciones de convivencia tensa, con las implicaciones que eso genera en el ecosistema (Hidalgo et al., 2009).

Siguiendo el esquema secuencial de D. Bell, distinguiendo los tres períodos mencionados (preindustrial, industrial y postindustrial), las ciudades muestran una serie de características diferenciadas para cada uno de ellos (Figura 4). 
Figura 4. Características de las ciudades en cada etapa

\begin{tabular}{|l|l|l|l|}
\hline Tema & Ciudad preindustrial & Ciudad industrial & Ciudad postindustrial \\
\hline Crecimiento & Moderado & Intenso & Bajo \\
\hline Flujo con el hinterland & Equilibrio & Centrípeto & Centrífugo \\
\hline Planeamiento & Espontáneo-Reforma & Proyectos & Plan \\
\hline Infraestructuras & Ausencia & Outdoor & Indoor \\
\hline Saneamiento & Ausencia & Medio & Elevado \\
\hline Viario & Animal & Ferrocarril & Automóvil \\
\hline Equipamiento dotacional & Bajo & Medio & Elevado \\
\hline $\begin{array}{l}\text { Localización y/o o } \\
\text { económicas }\end{array}$ & $\begin{array}{l}\text { Integración yespecia- } \\
\text { ligación actividades }\end{array}$ & $\begin{array}{l}\text { Concéntricos } \\
\text { Zonificación }\end{array}$ \\
\hline Modelo Residencia & Casco Histórico & $\begin{array}{l}\text { Cuadrícula } \\
\text { continua }\end{array}$ & Polígono Residencial \\
\hline Espacios públicos & Bajo & Alto \\
\hline Espacios verdes & Medio & Indoor & Amplios espacios \\
\hline Filosofía producción espacio & Prefordismo & Fordismo & Postfordismo \\
\hline
\end{tabular}

Fuente: Elaboración propia

En las sociedades postindustriales, la intensa suburbanización hizo que los crecimientos en la ciudad central fuesen comedidos (bajos). La periferia crecía, en buena parte, con antiguos residentes de los centros, atraídos por la reducción del precio en aquellos núcleos más alejados. La urbanización dominante se basaba en polígonos residenciales, acompañados de piezas zonificadas en las que se colocaban los grandes centros comerciales, de ocio, o empresariales. Todo ello, conectado por infraestructuras viarias en las que dominaba el automóvil. En general, todos los indicadores aparentan mejorar su nivel respecto al de la ciudad de la sociedad industrial. Se llevó por delante la vida de los barrios, el comercio asociado a ellos y el patrimonio arquitectónico popular.

Podemos entender esa ciudad postindustrial, contemporánea, como una ciudad ya heredada. Desde la perspectiva del planificador urbanístico, la ciudad de la que habla, es una ciudad de futuro, que supera algunas de las deficiencias de la actual. Podemos denominarla, como hace la Agenda 2030, como la ciudad sostenible. Un nuevo entorno que obedece a otro modelo de sociedad en su conjunto.

\section{LA CIUDAD COMO ESCENARIO}

La ciudad ${ }^{5}$ es el escenario del conflicto de intereses de los diferentes agentes que intervienen en ella (Krier, 1992). El interés que mueve a los agentes individuales en la producción del espacio puede ser diferente del colectivo. Este último es crucial, incluso discutible en cuanto a su existencia y preeminencia, además, de diverso y cambiante. De existir, debemos entender el interés colectivo no solo como la suma de los individuales ${ }^{6}$, sino como ente con personalidad propia y diferenciada de aquellos. El todo, al menos en este caso, no es la suma de las partes.

El interés colectivo puede medirse a partir de los derechos colectivos que cada sociedad recoge en cada momento histórico. Karel Vašák propuso, en 1977, que la historia del derecho recogía tres momentos o generaciones de los mismos. La primera focalizaba su atención en los individuales, la 
segunda en los económico sociales y la tercera, basada en derechos de las minorías de los pueblos y/ o de la solidaridad (Vašák, 1977). Todavía podríamos hablar de una cuarta, que podría entenderse como los derechos que superan a "nuestras" sociedades, para incluir a las sociedades venideras y al planeta en su conjunto, tal como se recoge en el concepto de sostenibilidad.

Esas variaciones de demandas obedecen a dos tipos de lógicas: a) por un lado, la transformación de los sujetos colectivos que los promueven y, b) por las coberturas satisfechas de los demandantes que, una vez alcanzan a cubrir ciertas necesidades, pasan a demandar otras nuevas.

Respecto a la primera de las lógicas, el agente social demandante de los derechos individuales era la burguesía; en la segunda generación, es el proletariado. La tercera es promovida por las minorías. La cuarta (la nueva generación de demandas emergiendo sutilmente en la actualidad), es obra de toda la comunidad, del conjunto de la ciudadanía.

Figura 5. Agentes sociales en cada momento histórico de demandas

\begin{tabular}{|l|l|l|l|}
\hline Generación & Momento histórico & Interés colectivo & Agente \\
\hline $1^{a}$ & Siglos XVIII y ss. & Derechos individuales & Burguesía \\
\hline $2^{a}$ & Siglo XIX y ss & Derechos colectivos & Proletariado \\
\hline $3^{a}$ & Siglo XX y ss & Derechos de minorías & Minorías \\
\hline $4^{a}$ & Siglo XXI y ss. & $\begin{array}{l}\text { Derechos } \\
\text { generaciones }\end{array}$ & Ciudadanía \\
\hline
\end{tabular}

Fuente: Elaboración propia

Respecto a la segunda lógica, en La revolúción silenciosa, Inglehart (1977) descubrió un cambio intergeneracional en los valores de las sociedades industrialmente avanzadas. En su libro El cambio cultural en las sociedades industriales avanzadas, explica y mide más en detalle ese cambio. Con una base de un gran número de encuestas de veintiséis naciones, desde 1970 a 1988, analiza los cambios culturales que se están dando, como el reemplazo de generaciones más viejas por otras más jóvenes, con las consiguientes consecuencias políticas y económicas. El cambio de valores de sociedades materialistas a postmaterialistas se refleja entre otros, en los siguientes aspectos (Figura 6):

Figura 6. Valores propios de cada sociedad según Inglehart

\begin{tabular}{|l|l|}
\hline MATERIALISTAS & POSTMATERIALISTAS \\
\hline Material & Espiritual \\
Renta & Salud \\
Comer & Bienestar \\
Mantener el orden del país. & Participar de las decisiones políticas. \\
Luchar contra el aumento dos precios. & Proteger la libertad de expresión \\
Crecimiento económico & Crecimiento sostenible \\
Fuerzas Armadas poderosas. & Estética de ciudades y campos \\
Mantener una economía estable & Sociedad menos impersonal y más humana \\
Luchar contra el crimen & Las ideas son más importantes que el dinero \\
\hline
\end{tabular}

Fuente: Elaboración propia, basado en Inglehart (1977).

Esos valores postmaterialistas emergentes que cobran relevantes se refieren, por ejemplo, a valorizar la estética, lo espiritual, lo ambiental o el disfrute de la libertad, la salud y el confort. Todo ello, en detrimento de la seguridad, el orden el dinero o la satisfacción de las necesidades materiales 
en general. Ese cambio, explica las nuevas demandas sociales y, por tanto, las urbanas; es, además, un cambio social que tiene su reflejo en la ciudad.

\section{LA CIUDAD DEFICIENTE}

Los cambios sociales que hemos comentado ejercen diferentes efectos sobre la ciudad. En concreto sobre el modelo deseado de la misma. Eso explica ciertas transformaciones que observamos en las políticas de planificación urbana. Las tendencias recientes son, en cierta medida, respuesta a la ciudad heredada y a los problemas que ésta traía, pero también siguen unos principios de corte político en sintonía con los procesos de cambio social comentados. Es oportuno diferenciar entre las tendencias de la ciudad heredada y las respuestas a esas inercias.

De la ciudad heredada destacamos 6 problemas: 1) En el interior de la ciudad, las elevadas densidades, con el consumo generado, así como el crecimiento del uso del automóvil privado (y del espacio dedicado al mismo) ha conllevado una fuerte congestión en los centros urbanos ${ }^{7}$; 2) La ciudad ha crecido en las últimas décadas, pero lo ha hecho con un efecto centrífugo, extendiéndose hacia las periferias, suburbanizándose y generando mucho sprawl (García Docampo, 2016; Borja, 2000). Aunque también se han producido suburbios altos y compactos, tanto estos como los de baja densidad, suponen un elevado consumo de suelo, especialmente viario interurbano, una elevada movilidad y dependencia hegemónica del automóvil (Trudeau \& Mallou, 2011, p. 424); 3) La inadecuación de oferta y demanda de vivienda (casas sin gente y gente sin casa) recoge un histórico problema de déficit de vivienda, mantenido durante décadas (Calo, 2015); 4) Contaminación y mala calidad del aire y, en ocasiones, también de las aguas. Esto va muy asociado a problemas de congestión, tráfico y también debido a la industria, al uso calefacciones y a la gestión de los residuos sólidos (Maldonado, 2009); 5) Desigualdad en el acceso a equipamientos y segregación espacial, de manera tal que barrios y ciudades enteras reproducen el sistema de estratificación social, al distribuir desigualmente en el espacio, dichas dotaciones; 6) La seguridad en la ciudad en general y en los espacios públicos más específicamente ha resultado una de las principales preocupaciones ciudadanas en muchos entornos urbanos. A la seguridad viaria, se une la delincuencia. Algo que Jane Jacobs resolvía o aminoraba, con “los ojos de la calle”, incrementando usos, tránsitos y heterogeneizando poblaciones (Jacobs, 1962).

Pero a estos hay que añadirle nuevos problemas que forman parte de la diagnosis de los retos de la ciudad más contemporánea: 1) Problemas medioambientales, debido a que las ciudades deben contribuir a generar nodos de infraestructura verde, pensando en otras especies de animales y plantes, además de en salud pública; 2) La gentrificación es un mal extendido por todas las ciudades, especialmente sus centros, expulsando a los residentes más vulnerables; 3) Todas nuestras ciudades se están turistificando y, con ello, derivando viviendas a usos turísticos y comercio de proximidad a otros pensados para visitantes ${ }^{8}$; 4) La extensión de la comodificación, genera cambios en la vida de las personas, transformando el comercio y las actividades económicas (Palomera, 2014); 5) La ciudad aparece guetificada, con barrios estigmatizados y, en general, una tendenciosa a la homogeneización social de los mismos que consolida las desigualdades (Blanco, 2009).

Los problemas de perceptibles de nuestras ciudades, bajo esta suma de amenazas, tanto heredados como contemporáneos, hacen precisa intervenciones de carácter político. Sobran dedos acusadores e incluso buenas intenciones. 
Nuestra presente relación con la crisis de la ciudad es profundamente ambigua: seguimos culpando a otros de una situación de la cual son responsables tanto nuestro incurable utopismo como nuestro desprecio (Koolhaas, 1996, p. 8).

La reacción reciente del urbanismo, para dar solución a esos problemas, se ha sustentado en cinco ejes, que funcionan como principios políticos orientadores de la planificación urbana y resultante de los procesos de cambio social observado en las sociedades contemporáneas. Esos principios son:

1) Territorios más sostenibles, superarando el sprawl y resolviendo la excesiva dependencia del automóvil y del elevado consumo de suelo, para llegar a una ocupación y un desarrollo de las actividades con menor degradación ecológica.

2) Demanda de una ciudad más amable, con nuevas modalidades de movilidad más sostenibles y menos tráfico, mejoras en la red de espacios públicos, mayor integración de la heterogeneidad social.

3) Accesibilidad a infraestructuras, equipamientos y dotaciones, con criterios heterogeneizantes. inclusivos y equitativos

4) Cambios en los modos de gobernanza del territorio, incrementando los niveles de participación, cooperación y planificación

5) Revalorización estética y protección de valores patrimoniales

Estos ejes se han integrado de diferente forma en algunas de las nuevas corrientes del urbanismo contemporáneo (Kelbaugh, 2000; 2007).

\section{LA CIUDAD PLANIFICADA}

El planeamiento urbanístico surge como una herramienta que genera la sociedad para coordinar los diferentes intereses que convergen en la producción y demanda del espacio (Gehl, 1971). Esos intereses han cambiado y evolucionado de la misma manera que lo hecho tanto la ciudad como la sociedad. Pero la concepción del mismo responde a lo que se entiende por interés colectivo y, éste, a su vez, va cambiando con la propia sociedad (Sennett, 2019). Los cambios sociales, tal como nos hace ver la sociología, se repiten frecuentemente en todas las sociedades, que pasan reiteradamente por fases y pautas similares. Los cambios en la concepción de los derechos responden a cambios en los valores sociales. La teoría del cambio de valores de Inglehart puede aportar luz a esta cuestión.

La ciudad preindustrial era una isla en el territorio rural circundante. En su interior, abundaban los espacios verdes, pero, en general, eran privados; el espacio público servía como soporte a las actividades mercantiles: la compra y venta se hacía, frecuentemente, en las calles y plazas. La ciudad industrial no solo derriba las murallas de la medieval, sino que cambia la función para albergar fábricas. En su interior aparecen ahora espacios públicos dedicados al ocio, incluyendo parques y jardines para disfrute de la población. Pero las reformas urbanísticas en ambos períodos eran limitadas a piezas, incluso de envergadura, como la de los ensanches. El plan vendrá más tarde, acompañando al modelo de ciudad postindustrial, sedes de amplias redes de actividades de servicios. 
Figura 7. La planificación de cada ciudad

\begin{tabular}{|l|l|l|l|}
\hline & Ciudad preindustrial & Ciudad industrial & Ciudad postindustrial \\
\hline Función urbana & Mercado & Producción & Servicios \\
\hline Relación con hinterland & Isla & Nodo & Red \\
\hline Flujos & Viaje & Transporte & Accesibilidad \\
\hline Espacios verdes & Innecesarios & Decorativos & Integrados \\
\hline Intervención plan & Reforma & Proyecto & Plan \\
\hline
\end{tabular}

Fuente: Elaboración propia

Recientemente, estamos evidenciando un nuevo urbanismo. Aparecen nuevas corrientes que centran su atención en los 5 ejes anteriormente mencionados: Crecimiento sostenible, espacios amables, inclusivos y con participación ciudadana en su diseño. Los nuevos paradigmas adoptan esta filosofía de manera diferente, entre las cuales aparecen las nuevas corrientes urbanísticas. Entre ellas, aparecen tres propuestas que muestran ese interés renovador: el Posturbanismo, el Everyday Urbanism y el New Urbanism. (Kelbaugh, 2000, 2007).

Si se va a hacer un nuevo urbanismo, no estará basado en las fantasías gemelas del orden y la omnipotencia; lo que tendrá que presentar será la incertidumbre; ya no estará dedicado a la disposición de objetos más o menos permanentes, sino a la irrigación de los territorios con posibilidades; ya no buscará configuraciones estables, sino la creación de ámbitos susceptibles de acomodar procesos que no admitan la cristalización en formas definitivas (Koolhaas, 1996, p. 8-9)

En su versión más pura, el Posturbanism está compuesto por elementos y piezas arquitectónicas generalmente grandilocuentes. Introduce las nuevas tecnologías y las funciones que la informática genera en la sociedad, tanto para trabajar, divertirse o vivir, para habilitar espacios propios de esa era. Rem Koolhaas, Zaha Hadidi, Steven Holl, Frank Gehry o Daniel Libeskind son algunos de los nombres asociados a esta corriente. En ciertas versiones más soft, se queda en un simple smart growth $^{9}$.

El Everyday urbanism es práctico, real, ejecutándose diariamente. Valora lo "efímero, la cacofonía, la multiciplidad y la diversidad" (Crawford, Chase \& Kaliski, 1999). Es un urbanismo "conversacional", abierto a las informalidades populistas, que separa el diseño físico del uso social de cada espacio. Fue inicialmente teorizado por Margaret Crawford, John Chase y John Kaliski en 1999. No se preocupa por la estética, sino por las actividades específicas de la vida diaria ${ }^{10}$. Constituye un enfoque empírico que refuerza situaciones y experiencias existentes que a menudo pasan desapercibidas en la vida cotidiana. A diferencia de las prácticas de diseño urbano, Everyday Urbanism no está interesado en la transformación completa de sitios, sino en la intensificación de estas experiencias al "trabajar junto con ellos, encima o detrás de ellos".

Según Bohl (2000), el nuevo urbanismo es un término genérico que abarca los conceptos tradicionales del vecindario de Andres Duany y Elizabeth Plater-Zyberk, las bolsas peatonales de Kelbaugh, los diseños de Peter Calthorpe y Shelly Poticha, y el enfoque de "quartiers" de Leon Krier (Knaap et al., 2005, p-109; Jepson et al., 2010, p. 417). Inicialmente, pretendía superar el sprawl, el aislamiento y mejorar la calidad de vida y la estética de las ciudades (Katz et al., 1994). Sus principios están articulados en la carta del Congreso para el Nuevo Urbanismo (CNU), fundado en 1993 por un grupo de arquitectos, planificadores y defensores del medio ambiente. Hoy, el 
CNU tiene más de veintitrés mil miembros en el mundo. Actualmente hay decenas de proyectos desarrollándose bajo el prisma de New Urbanism (Knaap et al., 2005, p. 109). Con frecuencia se cita como ejemplo práctico de New Urbanism el caso de Seaside (Florida).

David Harvey (2000) en un artículo publicado en La Vanguardia señalaba que "El nuevo urbanismo está en la cresta de la ola. Todo el mundo es su entusiasta defensor. Porque, al fin y al cabo, ¿a quién le gustaría que le llamasen 'viejo urbanista'?". En ese artículo clasifica las diferentes versiones en tres grupos: a) La versión Costa Este americana, con su modelo dominante de residencial mixto de alta densidad ${ }^{11}$; b) La versión británica del “pueblo urbano"12 ; c) La versión Costa Oeste americana, que genera barrios dispersos, integrados interna y regionalmente ${ }^{13}$.

Pero tanto el urbanista, como los políticos o cualquiera de los demás agentes que intervienen en la producción del espacio, son conscientes de esa lógica interna de la ciudad. Raramente asumen su responsabilidad; contrariamente, teorizan desde la retaguardia y formulan un "deber ser" en la que se sienten ajenos, “exiliados al mundo virtual” (Koolhaas, 1996, p. 8) ${ }^{14}$.

\section{LA CIUDAD SOSTENIBLE}

Es evidente que, a pesar de llevar décadas de planes urbanísticos generalizados en todas las ciudades, éstas presentan deficiencias y problemas como los anteriormente mencionados. Recurrentemente escuchamos que el urbanismo está en crisis, o que lo está la ciudad (Rubio Herrera, 2016). Ciertas frases se repiten de un decenio a otro: la crisis del urbanismo, el planeamiento urbanístico en la encrucijada, un nuevo enfoque para el planeamiento. La historia del planeamiento urbanístico parece un proceso continuo de introspección y reinvención" (Hebbert, 2000 , p. 82). Pero, frente a los fracasos del urbanismo, la ciudad es pujante. Adopta múltiples formas, se planifica y se escapa del plan $^{15}$. Incluso cambia de escala, de límites físicos, para concebirse más allá de sus periferias suburbanas, hasta integrarse en su región (Borja, 2000).

El siglo XX fue muy dañino para el planeta, casi letal. Tardamos, pero actualmente es imprescindible (y urgente) entender que es nuestra responsabilidad cuidarlo. No está totalmente asumida esa defensa, sino que tan solo comienza a estarlo. Los nuevos planes urbanísticos han avanzado mucho a este respecto, pero adolecen aún de graves carencias. El Everyday Urbanism, es acusado de mantener el foco en espacios demasiado pequeños, con visión poco global; el Posturbanism aparece, a su vez, como una ficción, además de que, en muchos casos, es incapaz de resolver los problemas de congestión, de perder la escala humana y de ser económicamente caro; el New Urbanism, con frecuencia es tildado de new suburbanism, por mantener aún muy elevada la dispersión (Gordon et al., 2007, p. 41), además de generar espacios falsamente idílicos ${ }^{16}$, socialmente segregativos y homogéneos.

Con lo mejor de la herencia de los nuevos paradigmas urbanísticos y recogiendo las tendencias sociales recientes, podemos caminar hacia un nuevo paradigma, que podemos denominar Urbanismo Sostenible

Antes de la generalización de los planes de urbanismo a todas las ciudades (y municipios), la práctica era de realizar proyectos, a escala más pequeña, siempre con la intención de mejorar la calidad de vida de las élites. A partir de mediados del siglo XX comienzan a elaborarse los planes de carácter municipal, democratizando y extendiendo a toda la ciudadanía los beneficios buscados. Pero el Urbanismo Sostenible supera también esa fase, al incrementar la escala (Rueda, 2010) ${ }^{17}$ y 
entender el planeamiento como una estrategia global, más allá del plan municipal, pensando en el planeta y en las generaciones venideras, llamadas a disfrutarlo. Los postulados estratégicos de ese nuevo paradigma son (Talen, 2002):

El planeta, entendido como nuestro hábitat, tiene que mejorar, en calidad y cantidad, nuestra vida, como humanos.

El planeta, con todos sus recursos naturales, tiene que ser conservado, en calidad y cantidad, para el disfruto de generaciones venideras.

El planeta, con todas sus especies, debe ser conservado para el disfrute de todas ellas, superando el antropocentrismo

En realidad, se pasa de una sostenibilidad industrial a otra postindustrial, siguiendo el esquema de D. Bell. La sostenibilidad post-industrial: 1) está pensada para generaciones actuales; 2) humanos como centro de referencia; 3) verde como decorado y esparcimiento. La sostenibilidad postindustrial: 1) está también pensada para generaciones futuras; 2) los humanos son una pieza relevante de un ecosistema que es el centro de la sostenibilidad: 3) Lo verde es una infraestructura en red, de manera que los parques urbanos dejan de ser islas para el ocio y esparcimiento humano, para convertirse en parte de una red continua en la que habitan múltiples especies.

El New urbanism incorporaba ya la sostenibilidad, pero de una manera insuficiente para garantizar la una buena sostenibilidad del hábitat a escala planetaria. No se trata de camuflar el actual desarrollo como sostenible sino de propiciar un planeta sostenible, con los cambios necesarios en el modelo. En el viejo urbanismo, lo "verde" funcionaba como un elemento decorativo. Aunque su función no fuese exclusivamente estética, se pensaba como espacio para el deleite y esparcimiento humano. Se concebían parques, jardines y bosques más grandes, incluso protegidos, se practicaba el ocio y se entendía como islas en las que se preservaba el medio, más o menos, intacto (natural). Lo "verde" era (es) simplemente parte del escenario. Los protagonistas eran otros y los roles que desarrollaban la acción, también.

El viejo paradigma mantenía unos objetivos que trataban de optimizar el bienestar humano en las ciudades. El nuevo paradigma cambia el centro de atención. Los seres humanos no son ese centro. Ahora, el medio ambiente, el planeta, ocupa esa posición. Se trata de optimizar su bienestar, su sostenibilidad y su eficiencia.

\section{LA CIUDAD AGENDADA}

“La batalla por la sostenibilidad se ganará o perderá en las ciudades" declaró Maurice Strong, secretario general de la Cumbre de Río, en $1992^{18}$. De hecho, en las ciudades y sus entornos se genera la mayor parte de la economía mundial, producida además en escalas de relativa mayor eficiencia energética pero también son las principales consumidores y generadoras de residuos y de huella de carbono. (Wackernagel, 1996).

Las voces que reclamaban una mayor atención a la sostenibilidad ambiental han pasado desde los artículos de la prensa científica (Goodlad, 1991; Pimentel, 1994), o del activismo ecologista (Hysing et al, 2017), a las carteras ministeriales (Howes et al., 2017). El informe de las Naciones Unidas "Nuestro Futuro Común" ${ }^{19}$, marca un hito es ese salto a las agendas políticas. En dicho documento se pone de manifiesto que el futuro de la humanidad está en peligro si no se cuida el planeta. Con el nuevo milenio, la necesidad de fomentar un entorno sostenible -temporal, económica y ambientalmente-, se han concretado en acuerdos gubernamentales internacionales 
que han derivado en estrategias nacionales. La Carta de Leipzig sobre Ciudades Europeas Sostenibles, de mayo del 2007, inauguraba un nuevo marco actual en el que se insiste no solo en la necesidad de un mayor desarrollo urbano coordinado entre las distintas administraciones sino también en prestar atención y cuidado al medio físico, en beneficio del planeta.

Tan solo un año después, en una reunión informal de ministros en Marsella (2008), se aprueba el European Reference Framework for Sustainable Cities (RFSC). En el mismo, se mantiene el paradigma de conjugar en la misma ecuación, productividad, justicia y ecología, que será refrendado durante la presidencia temporal española de la UE (en Toledo, en 2010). En su desarrollo práctico, se incluyen un conjunto de indicadores, herramientas de visualización y canales de intercambio de experiencias, con objeto de evaluar la buena marcha de las ciudades, revalidado por los 27, de manera oficial en el 2011, por la Comisión Europea.

En el año 2015, España, con otros 150 países, en la Cumbre de Desarrollo Sostenible promovido por las Naciones Unidas, firmó el acuerdo que aprobaba la Agenda 2030 para lograr un mundo más sostenible; "un plan de acción en favor de las personas, el planeta y la prosperidad" (ONU, 2015, p. 1). En él se incluyen 17 objetivos estratégicos, de entre los cuales, el 11, busca "lograr que las ciudades y los asentamientos humanos sean inclusivos, seguros, resilientes y sostenibles" (ONU, 2015:16). Para ello, se establecen 7 metas y tres orientaciones supletorias. Se establece así, un guión en el que es posible leer un rol decisivo de las ciudades para resolver problemas actuales y construir un mundo mejor.

El 25 de setiembre de 2015, en el marco de las Naciones Unidas, 193 países se comprometen a alcanzar 17 objetivos de desarrollo sostenible para el 2030. El Objetivo no 11 trata de lograr que las ciudades y los asentamientos humanos sean inclusivos, seguros, resilientes y sostenibles. Para conseguirlo, se proponen 9 metas que, resumidamente, sintetizamos como:

Figura 8. Ciudades sostenibles

Meta 11.1. Acceso a la vivienda para toda la población

Meta 11.2. Acceso al transporte

Meta 11.3. Urbanización inclusiva, participativa y sostenible

Meta 11.4. Protección del patrimonio cultural y natural

Meta 11.5. Reducción de la mortalidad causada por desastres naturales

Meta 11.6. Reducir la huella ecológica

Meta 11.7. Accesibilidad a zonas verdes y espacios públicos seguros

Meta 11.A. Mejorar la relación campo-ciudad

Meta 11.B. Planificar un desarrollo territorial sostenible y seguro

Meta 11.C. Construcción sostenible y resiliente

Fuente: ONU (2015)

\section{CONCLUSIONES}

1‥ Frente a los fracasos del urbanismo, la ciudad no solo persiste, sino que es pujante. Adopta múltiples formas, se planifica y se escapa del plan. En ocasiones, aparece intensiva, cogestionada; en otros desconcentrada, extensiva, sin densidad. Los procesos que intentan colmatarla, coserla, 
asearla, conectarla, a medio plazo, se agotan. La ciudad vive y supera los viejos planes buscando su propio espacio.

$2^{2}$. Hay síntomas de algunas de las direcciones de "cambio social" en nuestras sociedades. Estos cambios afectan a las demandas que, de manera colectiva, asumen la ciudadanía. En concreto, esas demandas, de tercera y cuarta generación (derechos de las minorías y derechos de la ciudadanía, respectivamente) se centran en los valores postmaterialistas y en lograr un hábitat más sostenible

$3^{\text {a }}$. Esos cambios han sido asumidos por una parte de los planificadores urbanos y del territorio. De hecho, es necesario ese compromiso, en defensa del planeta. Aunque no está institucionalizado, podemos denominar "urbanismo sostenible" a ese nuevo paradigma. En su génesis están, no sólo la tentativa de solucionar los problemas de la ciudad heredada en base a los principios postmaterialistas, sino también todo el bagaje de corrientes como el Posturbanism, el Everyday Urbanism y el New Urbanism.

$4^{\mathrm{a}}$. Los fundamentos diferenciadores de ese urbanismo sostenible son tres: la necesidad de referirse a la mejora de toda la especie humana, de ésta y próximas generaciones y de hacerlo en armonía con el bienestar del resto de las especies que habitan el planeta.

5‥ La agenda 2030 es un marco para el desarrollo de este nuevo paradigma urbanístico; encaja en esta demanda de un planeta más sostenible y es acorde con el cambio social que en esa línea se está observando

\section{REFERENCIAS BIBLIOGRÁFICAS}

Beatley, T. (1995). Planning and sustainability: The elements of a new (improved?) paradigm. Journal of planning literature, 9(4), 383-395. https://doi.org/10.1177/088541229500900405

Bell, D. (1973). El advenimiento de la sociedad post-industrial. Alianza Editorial.

Blanco, I. (2009). Gobernanza urbana y políticas de regeneración: el caso de Barcelona. Revista Española de Ciencia Política, 20(4), 125-146. https://recyt.fecyt.es/index.php/recp/article/view/37478

Borja, J. (2000). Ciudadanía y espacio público. Revista Foro, (40), 67-80.

Calo, E. (2015). El sistema residencial en España: componentes, funcionamiento y necesidades de vivienda [Tesis Doctoral, Universidade da Coruña]. https://ruc.udc.es/dspace/handle/2183/15915

Crawford, M., Chase, J. \& Kaliski, J. (1999). Everyday Urbanism. Monacal Press.

Chueca Goitia, F. (1968). Breve história do urbanismo. Presença.

De Mattos, C.A. (2007). Modernización capitalista y revolución urbana en América Latina: cinco tendencias genéricas. En Geraiges de Lemos, A.I., Arrollo, M. y Silveira, M.L. (eds.). América Latina: cidade, campo e turismo. CLACSO.

García Docampo, M. (2016). Recent Residential Mobility in Spain. Mediterranean Journal of Social Sciences, 7(3 S1), 192. https://doi.org/10.5901/mjss.2016.v7n3s1p192

García Docampo, M. y Varela García, T. (2021). Transformaciones urbanas y cambios en el planeamiento: el caso español. En Guimaraes, S. (ed.). Espaço aberto: Reflexoes iberoamericanas sobre cidade e sociedade, pp. 38-58. Repositorio CEUB.

Gehl, J. (1971). La humanización del espacio urbano. La vida social entre los edificios. Reverte.

Giddens, A. (2006). La constitución de la sociedad. Amorrortu.

Goodland R., Daly, H. \& El Serafi, S. (1991). Environmentally Sustainable Development: Building on Brundtland. Banco Mundial, 
Gordon, D., \& Vipond, S. (2005). Gross density and new urbanism: Comparing conventional and new urbanist suburbs in Markham, Ontario. Journal of the American Planning Association, 71(1), 41-54. https://doi .org/10.1080/01944360508976404

Harvey, D. (26 de noviembre de 2000). El nuevo urbanismo y la trampa comunitaria. La Vanguardia.

Hebbert, M. (2000). El Grupo de Trabajo -Task Force- y el nuevo enfoque del urbanismo británico. Urban, (4) 82-90. http://polired.upm.es/index.php/urban/article/view/298

Hebbert, M. (2003). New urbanism—the movement in context. Built Environment, 29(3), 193-209. https:// www.jstor.org/stable/23287649

Hidalgo, R., y Borsdorf, A. (2009). El crecimiento urbano en Europa: conceptos, tendencias y marco comparativo para el área metropolitana de Santiago de Chile. Estudios geográficos, 70(266), 181-203. https://doi.org/10.3989/estgeogr.0449

Howes, M., Wortley, L., Potts, R., Dedekorkut-Howes, A., Serrao-Neumann, S., Davidson, J., Smith, T. \& Nunn, P. (2017). Environmental sustainability: a case of policy implementation failure? Sustainability, 9(2), 165. https://doi.org/10.3390/su9020165

Hysing, E \& Olsson, J. (2018). Green Inside Activism for Sustainable Development: Political Agency and Institutional Change. Palgrave.

Inglehart, R. (1977). The Silent Revolution. Changing Values and Poltical Styles Among Western Publics. Princenton University Press.

Jacobs, J. (1962). Muerte y vida de las grandes ciudades. Península.

Jepson Jr, E.J., \& Edwards, M.M. (2010). How possible is sustainable urban development? An analysis of planners' perceptions about new urbanism, smart growth and the ecological city. Planning Practice \& Research, 25(4): 417-437. https://doi.org/10.1080/02697459.2010.511016

Katz, P. (1994). The new urbanism: Toward an architecture of community. McGraw-Hill.

Kelbaugh, D. (2000). Three paradigms: New urbanism, everyday urbanism, post urbanism-An excerpt from the essential common place. Bulletin of Science, Technology \& Society, 20(4), 285-289. https://doi.org /10.1177/027046760002000406

Kelbaugh, D. (2007). Toward an integrated paradigm: Further thoughts on the three urbanisms. Places Journal, 19(2). https://placesjournal.org/article/further-thoughts-on-the-three-urbanisms/?cn-reloa ded $=1$

Knaap, G., \& Talen, E. (2005). New urbanism and smart growth: a few words from the academy. International Regional Science Review, 28(2), 107-118. https://doi.org/10.1177/0160017604273621

Koolhaas, R. (1996). ¿Qué fue del urbanismo? Revista de Occidente, (185), 4-10. http://www-etsav.upc.es/ personals/monclus/cursos/koolhaas.htm

Krier, L. (1992). Architecture \& Urban Design 1967-1992. Academy Editions.

Maldonado, J. M. (2009). Ciudades y contaminación ambiental. Revista de ingeniería, (30), 65-71. https://w ww.redalyc.org/articulo.oa?id=121015710002

ONU (2015). Resolución aprobada por la Asamblea General de las Naciones Unidas el 25 de septiembre de 2015, A/RES/70/1. Transformar nuestro mundo: la Agenda 2030 para el Desarrollo Sostenible. https ://unctad.org/system/files/official-document/ares70d1_es.pdf

Palomera, J. (2014). How did finance capital infiltrate the world of the urban poor? Homeownership and social fragmentation in a Spanish neighborhood. International Journal of Urban and Regional Research, 38(1), 218-235. https://doi.org/10.1111/1468-2427.12055

Pimentel, D. \& Pimentel, M. (1994). The Demographic and environmental consequences of the green revolution. Focus, 4(1), 37-44. 
Rees, W. E. (1995). Achieving sustainability: reform or transformation?. Journal of planning literature, 9(4), 343-361. https://doi.org/10.1177/088541229500900402

Rubio Herrera, Y.C. (2016). El principio de accesibilidad universal como nuevo paradigma urbanístico [Trabajo Fin de Grao, Universidad de La Laguna].

Rueda, S. (2010). L'urbanismo ecologico. Territorio della Ricerca su Insediamenti e Ambiente. Rivista internazionale di cultura urbanistica, 3(6), 127-140. https://doi.org/10.6092/2281-4574/1817

Sennett, R. (2019). Construir y habitar: ética para la ciudad. Anagrama.

Talen, E. (2002). The social goals of new urbanism. Housing policy debate, 13(1), 165-188. https://doi.org/ $10.1080 / 10511482.2002 .9521438$

Trudeau, D. \& Mallou, P. (2011). Suburbs in disguise? Examining the Geographies of the New Urbanism. Urban Geography, 23(3), 424-447. https://doi.org/10.2747/0272-3638.32.3.424

Vašák, K. (1977). Les différents catégories des droits de l’homme. En Lapeyre, A., de Tinguy, F. et Vašák, T. (eds.). Les dimensions universelles des Droits de l'Homme, pp. 297-316. UNESCO-Bruylant.

Wackernagel, M. (1996). ¿Ciudades sostenibles? Ecología Política, (12), 43-50. https://www.jstor.org/stab le/20742894

\section{NOTAS}

Manuel García Docampo es licenciado en Ciencias Políticas y Sociología por la Universidad Complutense de Madrid; Diplôme d'Études Aproffondies (DEA), por la École de Hautes Études en Sciences Sociales de París; doctor en Sociología por la Universidade da Coruña; y profesor titular de Universidad, adscrito al Departamento de Sociología y Ciencia Política y de la Administración de la UdC.

Contacto: docampo@udc.es

1 Intentar explicar la evolución de la sociedad a partir de identificar una serie "fases" o "estadios" ha sido una estrategia recurrente en Ciencias Sociales. Se trata de recurso para interpretar los procesos de Cambio Social muy usual desde el inicio de la Sociología como Ciencia. Así, la Ley de los Tres Estadios de Comte (1842), el paso de Comunidad a Sociedad de Tönnies (1887), el Materialismo Histórico de Marx (1848) o la División Social del Trabajo de Durkheim (1893).

2 Entre los domésticos, en una época en que la tracción móvil era animal, eso es una obviedad.

3 La historia de las ciudades, hasta la actualidad, ha seguido dos tipos de procesos. Unos, de crecimiento regular y continuo y, otros, convulsos y puntuales, en ocasiones, con crecimientos extraordinariamente intensos y, en otras, con crisis relevantes. Respecto a estas últimas, la mortalidad catastrófica causada por epidemias que visitaban por oleadas las ciudades de la Alta Edad Media y Antiguo Régimen, diezmando fuertemente la población urbana. Los momentos de mayor intenso crecimiento, por su parte, fueron, por un lado, el derribado de las murallas para expandir el incremento provocado por la revolución industrial y, posteriormente, la extensión de la ciudad a suburbios discontinuos, con la llegada del automóvil. ${ }^{4}$ Rubiano, M.J. et al. (2020) "¿Reanudar la fumigación aérea de cultivos ilícitos en Colombia? Un resumen de la literatura científica", Comentario de Política \# 2. CESED - Universidad de los Andes, pág. 14. Disponible en https://cesed.uniandes.ed u.co/wp-content/uploads/2021/03/Reanudar-fumigaci\%C3\%B3n-de-cultivos_pdf.

4 Con la aparición de la industria, el crecimiento se intensifica y, aunque la ciudad derrumba las murallas y se extiende, mantiene un crecimiento centrípeto. Adopta, a su vez, el nuevo modo de vida, con altas tasas de movilidad. Cuando las infraestructuras se incrementan y los tiempos de desplazamiento se reducen, con la llegada de la sociedad postindustrial, el crecimiento se vuelve centrífugo. Los centros urbanos dejan de crecer, incluso pierden población, en detrimento de las periferias suburbanas.

5 "Entendiendo por ciudad este producto físico, político y cultural complejo, europeo y mediterráneo, pero también americano y asiático, que hemos caracterizado en nuestra ideología y en nuestros valores como concentración de población y de actividad, mixtura social y funcional, capacidad de autogobierno y ámbito de identificación simbólica y de participación cívica. Ciudad como encuentro, intercambio, ciudad igual a cultura y comercio. Ciudad de lugares y no simple espacio de flujos." (J. Borja, 2000). 
Los intereses individuales no sólo están representados por los propietarios, sino por los demás agentes intervinientes en la producción del espacio: promotoras, constructoras, inmobiliarias, arquitectos, ...

La contaminación y congestión has sido generalizadas y prácticamente todas las grandes ciudades han tenido que implementar planes para evitar un colapso de tráfico y de la contaminación generada en los centros urbanos.

8 Las viviendas que tradicionalmente se dedicaban a residencia de la población se dedican ahora, en porcentajes significativos, a albergar a turistas y visitantes (turistificación). La incidencia en el mercado, reduciendo la oferta, incrementando los precios, conllevan expulsión de los residentes menos pudientes. Así mismo, las actividades económicas de proximidad, pierden peso respeto de las utilidades de los residentes, para ganarla respecto de los turistas (De Mattos, 2007).

9 Una densidad más alta de crecimiento (justificada quizá por una referencia a los conceptos de comunidad y de barrio) en torno a núcleos o centros ya existentes (en oposición a la urbanización caótica), se considera más bien como una respuesta a la presión excesiva sobre los espacios públicos, las infraestructuras (escuelas, agua potable, tratamiento de aguas residuales, carreteras) y el medio ambiente (por ejemplo, la pérdida de suelo agrícola o de hábitats de alto valor). El concepto de "crecimiento inteligente" ha cobrado un atractivo nacional en Estados Unidos, como el único camino para reorientar la urbanización sin límites y caótica hacia una vía más eficiente y respetuosa con el medio ambiente.

10 Por ejemplo, el valor de los espacios públicos y la vida comunitaria está rebosante de mercados callejeros, vendedores ambulantes de alimentos y murales creados orgánicamente; este estallido creado por la vida comunitaria da como resultado mejoras en el espacio público que el "urbanismo cotidiano" entiende como una "mejora por apropiación" o como una apropiación desafiante de lugares en la ciudad con actividades urbanas temporales y efímeras.

11 Aunque la huella ecológica resultante es de las más óptimas, se trata de ciudades congestionadas en las que sus habitantes siguen dedicando muchas horas a los desplazamientos (eso sí, en transporte colectivo) y habitadas por élites sociales en islas de suburbios más depauperados. Son núcleos urbanos atractivos, con una ingente oferta cultural y elevados niveles de seguridad. El uso residencial está acompañado por el comercial y de ocio. Estos últimos son el objeto de consumo de esas élites, además de focos de atracción de un importante volumen de visitantes que cogestionan aún más esos nodos.

12 Combina la nostalgia por un período perdido con una pizca de conciencia social e intenta aportar elementos laborales y comerciales a una fisonomía urbana caracterizada por un fácil acceso en la propia localidad. La idea de pueblo urbano goza de un extendido atractivo que abarca a todo el espectro social. Grupos étnicos, comunidades obreras y élites privilegiadas han adoptado esta idea con entusiasmo

13 Sitúa los núcleos de barrio tradicional en el seno de un plan regional más integrado de infraestructuras de transporte para enlazar los puestos de trabajo espacialmente dispersos, las zonas comerciales y las instalaciones de ocio. Transige, por una parte, con la dispersión de tales factores, pero trata de recuperar los ideales de una convivencia vecinal más íntima y entrañable y de una vida de comunidad.

14 "Lo que convierte esta experiencia en desconcertante [... ] es la desafiante persistencia y aparente vigor de la ciudad, a pesar del fracaso colectivo de todos los agentes que actúan sobre ella o tratan de influirla creativa, logística y políticamente" (Koolhaas, 1996: 6).

15 Pero tanto el urbanista, como los políticos o cualquiera de los demás agentes que intervienen en la producción del espacio, son conscientes de esa lógica interna de la ciudad. Raramente asumen su responsabilidad; contrariamente, teorizan desde la retaguardia y formulan un "deber ser" en la que se sienten ajenos, "exiliados al mundo virtual" (Koolhaas, 1996: 8).

16 El nuevo urbanismo rebosa de nostalgia por una idealizada vida de pequeña población y estilo de vida rural que nunca existió. Las realidades de tales lugares estuvieron con frecuencia caracterizadas por un ambiente represivo y limitador, más que por ser realidades seguras y satisfactorias (al fin y al cabo, ésta fue la clase de mundo del cual las generaciones de emigrantes ansiaban huir, y precisamente no acudían a él en tropel). Y además, el nuevo urbanismo, en la manera en que es descrito, muestra señales abundantes de represiones y exclusiones en nombre de algo llamado "comunidad" y "barrio" o "vecindario".

17 La planificación urbana requiere pasar de una visión del plano a cota cero, del actual urbanismo, a otra que triplica esa visión, añadiendo una capa de subsuelo, otra de planta y una tercera de altura. Cualquiera de ellas es apta para la biodiversidad ecológica. En altura, por ejemplo, las fachadas dejan de ser elementos decorativos para integrarse en el ecosistema captando y reciclando energía, funcionando como soporte vegetal y ampliando las funciones bióticas en su conjunto (Rueda, 2010). 
18 El evento fue una de la Cumbres de la Tierra -organizadas por la ONU- celebrada en Río de Janeiro en Brasil del 3 al 14 de junio de 1992, en la que participaron 178 países. Fue sucesora de la Conferencia sobre el Medio Humano (Suecia, 1972), 20 años después, y denominada oficialmente como Conferencia de las Naciones Unidas sobre Medio Ambiente y Desarrollo (CNUMAD), si bien popularmente conocida como Cumbre de Río o de la Tierra.

19 Desde 1987, cuando Our Common Future estableció “sostenibilidad" como parte del léxico global, este fue extendiéndose rápidamente por la literatura urbanística. Entre los desarrollos pioneros, destacan Rees (1995) y Beatley (1995). Desde entonces, muchos otros reconocen su potencial como un marco teórico para la práctica de planificación y el desarrollo de comunidades en los EE. UU. (Jepson et al., 2010). 